\title{
Video Motion Analysis untuk Evaluasi Performansi Gerakan Penusukan pada Robot Pemosisi Jarum Spinal
}

\author{
1Instrumentasi dan Kontrol, Fakultas Teknologi Industri, Institut Teknologi Bandung, Indonesia
}

(corresponding author) jessicasutanto9821@gmail.com*)

\begin{abstract}
Abstrak
Dalam beberapa dekade terakhir ini, penggunaan USG sebagai umpan balik citra dalam prosedur intervensional invasif minimal semakin meningkat. Namun, pencitraan tersebut memiliki masalah krusial, yaitu visibilitas jarum yang tidak konsisten. Untuk mempelajari faktor yang mempengaruhi visibilitas tersebut dibutuhkan sebuah sistem robot pemosisi jarum yang memenuhi beberapa kriteria, diantaranya (i) jarum dapat bergerak bebas dalam field of view (FOV) transduser dan posisi jarum sejajar dengan transduser, (ii) mampu melakukan variasi posisi jarum ke arah sumbu X dan Z, rotasi, dan gerakan penusukan. Sistem robot tersebut akan diuji tingkat akurasi dan linearitas dengan melakukan skenario gerakan penusukan dan gerakan pemosisian ujung jarum pada koordinat kisi. Untuk mengevaluasi kemampuan dalam membuat trajektori garis lurus dan pemosisian jarum pada kisi, digunakan pendekatan video motion analysis untuk mendapatkan parameter pengujian, seperti RMSE dan linearitas, dari koordinat selama penusukan. Perekaman video dikondisikan secara khusus agar informasi jarum dapat dicitrakan dengan kontras optimal dan pada 30 fps. Posisi ujung jarum (koordinat $(x, y)$ ) dideteksi dengan melakukan segmentasi citra dan kontras maksimum pada penanda ujung jarum. Hasil pengujian menunjukkan pendekatan analisa performansi proses penusukan jarum menggunakan video motion analysis dapat digunakan untuk uji performansi robot pemosisi jarum spinal.

Kata Kunci: video motion analysis, segmentasi citra, kontras maksimum, jarum spinal
\end{abstract}

\section{Pendahuluan}

Prosedur intervensional invasif minimal merupakan suatu penanangan atau proses diagnosis yang melibatkan proses pengirisan dan pemasukan alat ke dalam tubuh. Pada umumnya, proses ini menggunakan bantuan umpan balik citra berupa ultrasonografi (USG). Namun, penggunaan USG ini memiliki masalah visibilitas jarum yang tidak konsisten. Dari laporan klinis para dokter, terdapat lebih dari 100 prosedur dengan bantuan USG yang memiliki permasalahan visibilitas pada ujung jarumnya [1]. Padahal visibilitas jarum yang konsisten sangat penting karena dapat meningkatkan tingkat keberhasilan prosedur dan mempercepat waktu pelaksanaan prosedur.

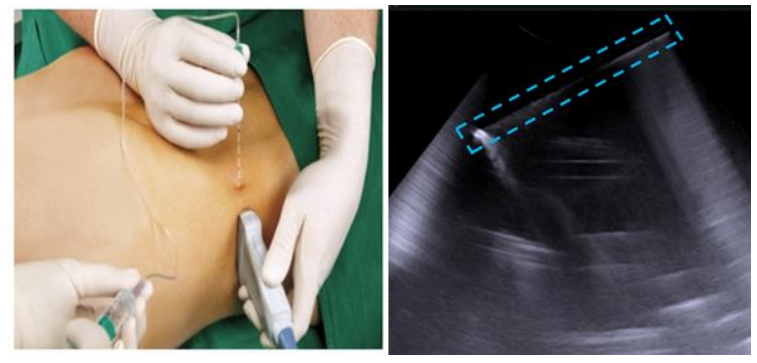

Gambar 1. prosedur intervensional invasif minimal (kiri) dan contoh hasil citra USG yang visibilitas jarumnya tidak kosisten (kanan)

Pentingnya konsistensi visibilitas jarum tersebut mendorong munculnya kebutuhan untuk melakukan pengujian terhadap parameter yang mempengaruhinya. Berdasarkan penelitian sebelumnya, diperoleh bahwa perambatan gelombang ultrasonik, perbedaan karakterisitik akustik antar medium, serta bentuk dan dimensi yang unik dari jarum merupakan parameter parameter yang dapat mempengaruhi fenomena fisis perambatan dan interaksi gelombang (hamburan resonansi) pada jarum [2].

Untuk melakukan pengujian terhadap parameter tersebut, dibutuhkan suatu robot pemosisi jarum yang memenuhi beberapa kebutuhan spesifik, sebagai berikut. (i) mampu memvariasikan posisi jarum, (ii) menghasilkan gerakan yang konsisten, akurat, dan presisi (iii) posisi jarum sejajar dengan posisi transduser, namun dapat bergerak bebas di dalam FOV transduser. Sistem robot tersebut perlu diuji dengan melakukan skenario gerakan pensukan pada berbagai posisi jarum dan gerakan pemosisian ujung jarum pada koodinat kisi. Pengujian ini bertujuan agar sistem robot tersebut memenuhi kebutuhan spesifik yang dibutuhkan. Oleh karena itu, untuk mengevaluasi kinerja sistem robot tersebut, pada penelitian ini, digunakan pendekatan video motion analysis untuk mendapatkan nilai parameter yang dapat digunakan sebagai ukuran kemampuan robot.

\section{Diskusi}

Video motion analysis merupakan sebuah pendekatan yang digunakan untuk mendapatkan informasi dari objek bergerak di dalam sebuah video. Video motion analysis ini umumya digunakan dalam cabang olahraga ataupun rehabilitasi untuk membantu para dokter dan pelatih mengamati dengan cermat faktor 
penyebab cidera. Namun, pada penelitian ini video motion analysis akan digunakan untuk mendapatkan posisi atau titik koordinat jarum yang diperlukan dalam perhitungan parameter parameter evaluasi kinerja sistem robot, seperti parameter RMSE, linearitas, standar deviasi, dan standar kesalahan regresi.

Pengujian kinerja tersebut dilakukan dengan mengevaluasi 2 skenario gerakan, yaitu gerakan penusukan dari kedalaman $1-5 \mathrm{~cm}$ dengan sudut penusukan $45^{\circ}$ dan gerakan pemosisian ujung jarum pada koordinat kisi berukuran 3x3. Adapun objek dan peralatan yang digunakan pada penelitian ini adalah sebagai berikut.

1. Jarum spinal $25 \mathrm{G}$ dengan panjang $9 \mathrm{~cm}$ dan terbuat dari stainless steel sebagai objek perekaman.

2. Kamera Nikon DX $1 / 1,8$ “ dengan panjang fokus $35 \mathrm{~mm}$.

\subsection{Metodologi Pengujian menggunakan Pendekatan Video Motion Analysis}

Pengujian ini dilakukan di ruangan dalam keadaan gelap. Pertama - tama, kamera Nikon DX disiapkan dengan jarak antara jarum dan kamera sebesar $58 \mathrm{~cm}$. Selanjutnya, jarum yang digunakan diwarnai putih pada ujung jarumnya. Hal ini untuk mempermudah pengolahan citra pada MATLAB. Pada pengujian ini juga digunakan layar hitam sebagai latar belakang pengambilan gambar jarum dengan jarak antara layar dan kamera sebesar $80,5 \mathrm{~cm}$. Hal ini bertujuan agar ujung jarum yang diwarnai putih terlihat lebih kontras pada saat perekeman. Setelah itu, dilakukan perekaman gerakan jarum, yaitu gerakan penusukan dari kedalam $1-5 \mathrm{~cm}$ dengan sudut penusukan $45^{\circ}$ dan gerakan pemosisian ujung jarum pada koordinat kisi berukuran $3 \times 3$.

Setelah direkam, video tersebut kemudian dikonversikan menjadi kumpulan gambar (30 frame per second (fps)) dengan bantuan perangkat lunak 'video converter'. Kumpulan gambar tersebut selanjutnya diolah citranya dengan menggunakan perangkat lunak MATLAB. Adapun pengolahan citra menggunakan MATLAB ini bertujuan untuk mendapatkan informasi posisi jarum, yaitu koordinat sumbu-x (horizontal) dan sumbu-y (vertikal). Informasi posisi jarum tersebut diperoleh dengan mencari titik ujung jarum yang telah diwarnai putih atau mencari informasi posisi citra dengan warna kontras optimal.

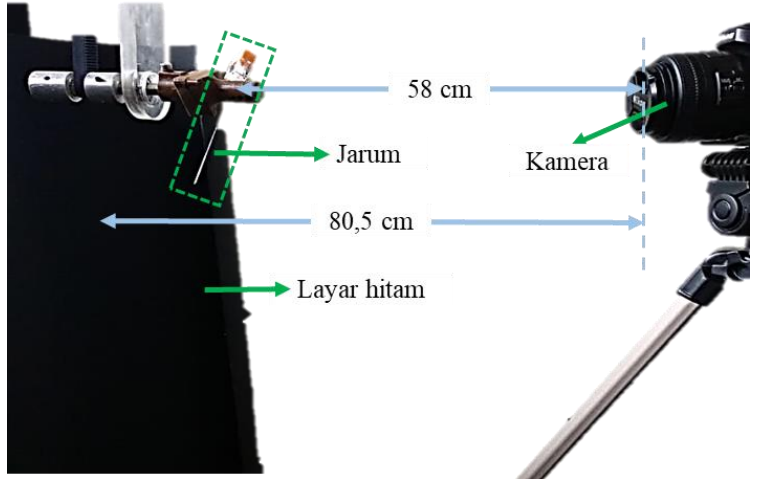

Gambar 2. konfigurasi pengujian menggunakan pendekatan video motion analysis

Namun, sebelum informasi tersebut dapat diperoleh, sebelumnya kumpulan gambar tersebut dipotong ke dalam ukuran yang lebih kecil atau hanya terlihat ujung jarum untuk mempermudah pencarian warna yang lebih kontras dan mengurangi adanya noise (warna putih lain yang muncul akibat resolusi kamera saat perekaman). Akan tetapi, ukuran potongan gambar tersebut harus konstan untuk sekumpulan gambar dalam sebuah video. Hal ini dikarenakan untuk menjaga konsistensi titik nol koordinat.

Setelah diperoleh informasi posisi jarum, selanjutnya data koordinat $\mathrm{x}, \mathrm{y}$ jarum dalam satuan pixel diolah menggunakan perangkat lunak Microsoft Office Excel. Untuk mendapatkan nilai parameter - parameter yang dibutuhkan, yaitu RMSE, standar deviasi, linearitas, dan standar kesalahan regresi, kumpulan data tersebut harus dikonversikan terlebih dahulu ke dalam satuan millimeter $(\mathrm{mm})$ atau centimeter $(\mathrm{cm})$.

Untuk mencari tingkat akurasi posisi jarum yang ditentukan dengan parameter RMSE perlu dicari nilai panjang/jarak standar pada jarum yang bertujuan untuk menghilangkan faktor field of view dari kamera. Field of view (FOV) kamera ini menyebabkan terdapatnya perbedaan antara jarak pada gambar yang terekam dengan jarak yang sebenarnya sehingga data menjadi tidak akurat. Nilai FOV ini bergantung pada optical format, fokus (focal length), dan jarak antara kamera dengan objek sehingga pengaturan posisi kamera, jarum, dan layar sangat mempengaruhi nilai faktor pengali yang akan digunakan sebagai nilai untuk mengatasi masalah FOV ini. 
Seminar Nasional Instrumentasi, Kontrol dan Otomasi (SNIKO) 2018 Bandung, Indonesia, 10-11 Desember 2018

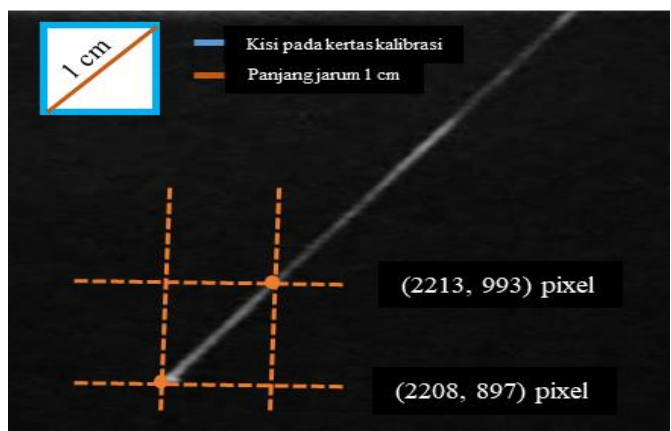

Gambar 3. posisi koordinat jarum berukuran $1 \mathrm{~cm}$ pada hasil citra rekaman

Dengan menggunakan perangkat lunak online 'FOV Calculator' diperoleh besarnya FOV yang terjadi pada lokasi jarum adalah $15,5 \mathrm{~cm}$ dan FOV yang terjadi pada lokasi layar adalah $30,7 \mathrm{~cm}$. Dengan kedua nilai tersebut, diperoleh besarnya faktor pengali $(k)$ yang merupakan perbandingan antara FOV pada lokasi jarum dengan FOV pada lokasi layar adalah sebesar 0,50. Selain itu, perlu dicari juga nilai panjang jarum $1 \mathrm{~cm}$ pada layar (jarak standar pada layar) yang terekam kamera. Dari hasil pengujian didapatkan jarak standar pada layar tersebut diwakili oleh titik koordinat $\left(\mathrm{x}_{1}\right.$, $\left.y_{1}\right)$ sebesar $(2208,897)$ pixel dan titik koordinat $\left(x_{2}, y_{2}\right)$ sebesar $(2213,993)$. Dengan persamaan pythagoras, diperoleh jarak standar pada layar sama dengan 96,13 pixel.

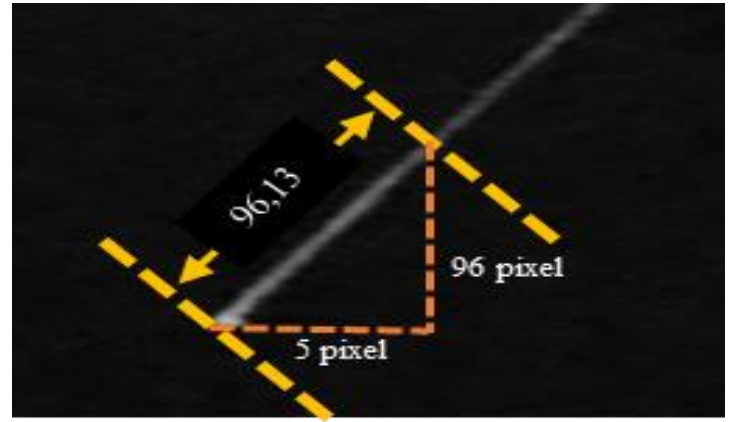

Gambar 4. panjang jarum $1 \mathrm{~cm}$ dari sudut pandang mata sama dengan panjang jarum 96,13 pixel dari sudut pandang kamera pada layar

Dengan mengalikan faktor pengali ke jarak standar pada layar diperoleh panjang jarum $1 \mathrm{~cm}$ pada jarum itu sendiri (jarak standar pada lokasi jarum), yaitu sebesar 48,53 pixel. Jika dikonversikan ke dalam satuan centimeter, diperoleh jarak standar pada jarum adalah sebesar $1,26 \mathrm{~cm}$ (1 $\mathrm{cm}$ panjang sebenarnya = $1,26 \mathrm{~cm}$ panjang jarum pada gambar).
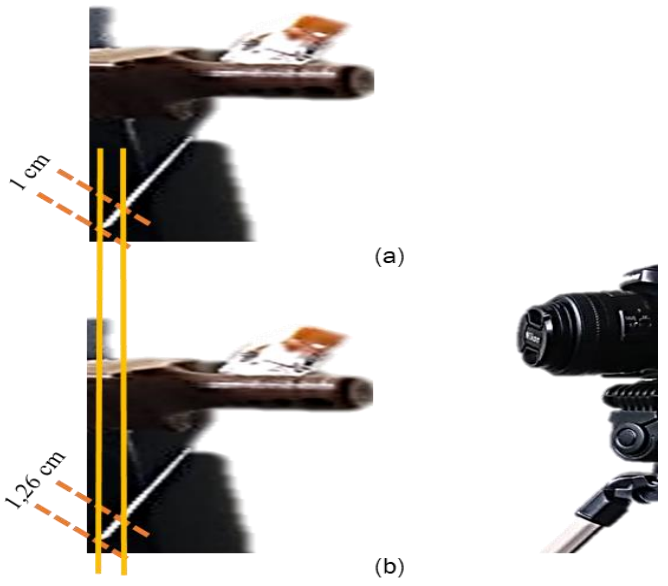

Gambar 5. panjang jarum $1 \mathrm{~cm}$ dari sudut pandang mata (gambar a) sama dengan $1,26 \mathrm{~cm}$ dari sudut pandang kamera pada lokasi jarum (gambar b)

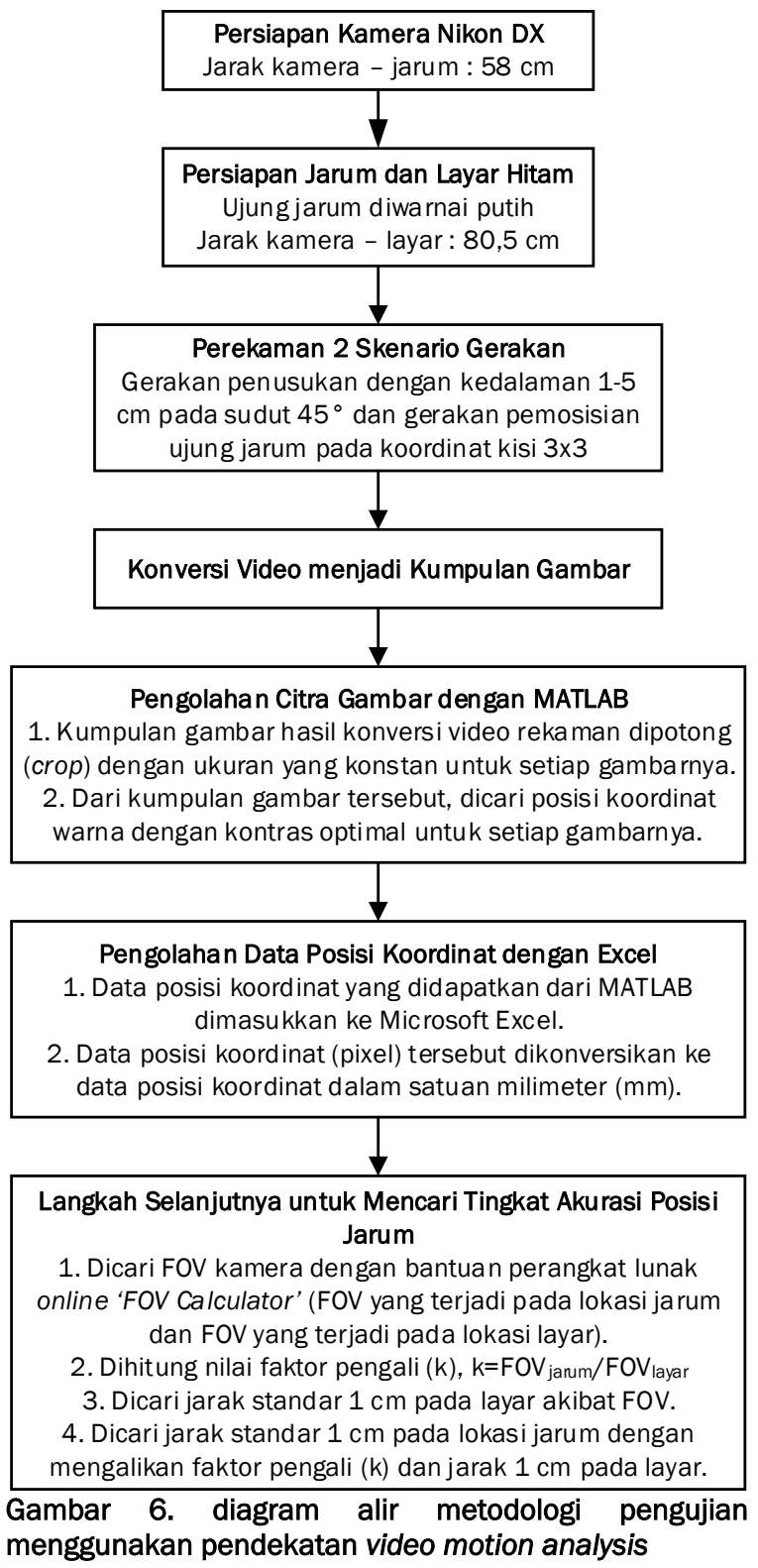




\subsection{Hasil Citra Pengujian menggunakan Pendekatan Video Motion Analysis}

Berikut ini merupakan gambaran hasil citra dari saat perekaman hingga pengolahan menggunakan MATLAB.

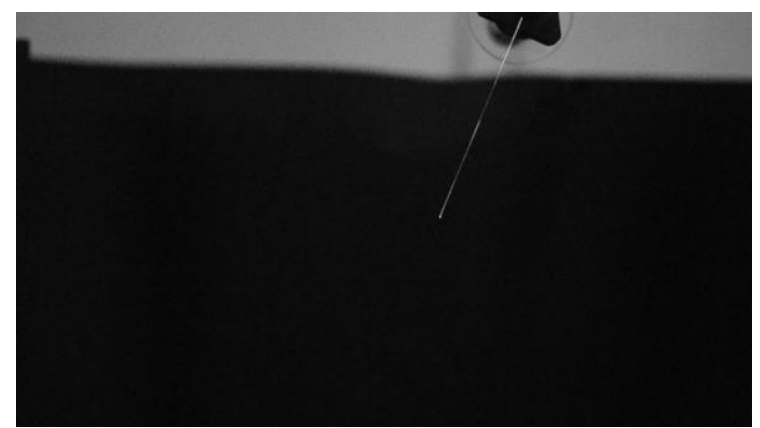

Gambar 7. contoh citra hasil rekaman menggunakan kamera Nikon

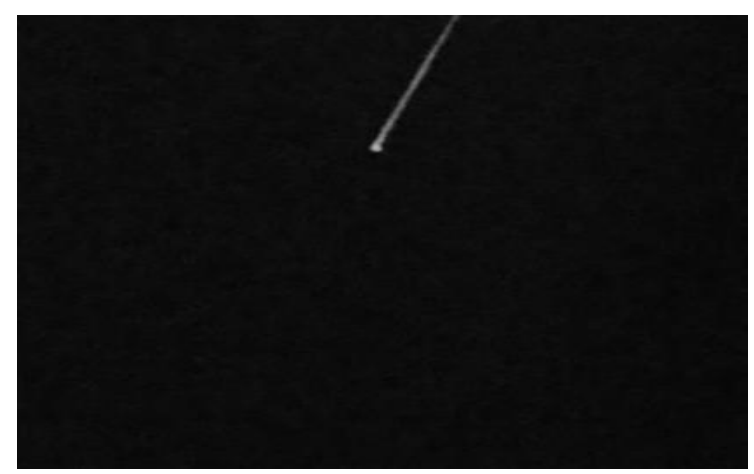

Gambar 8. contoh hasil citra yang sudah dipotong dengan ukuran frame yang diinginkan menggunakan MATLAB

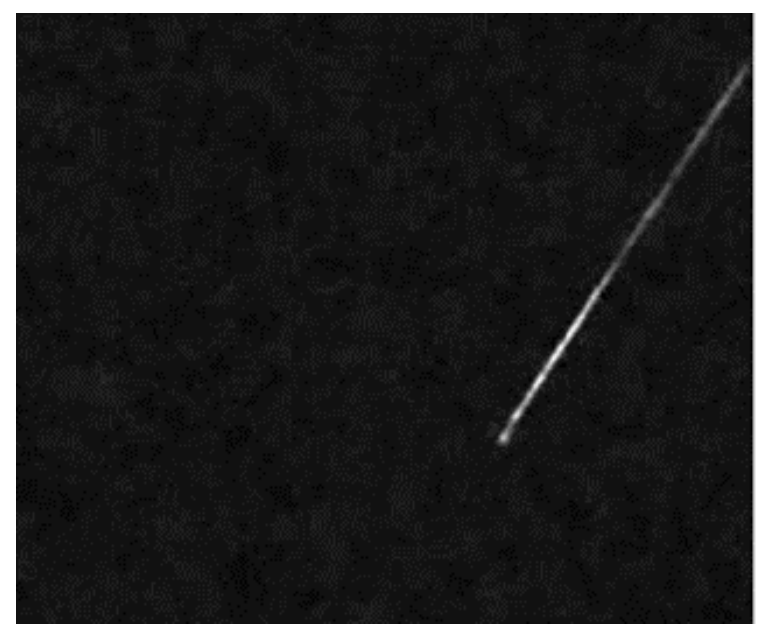

Gambar 9. contoh hasil citra jarum dengan kontras warna paling optimal tidak terdapat pada ujung jarum

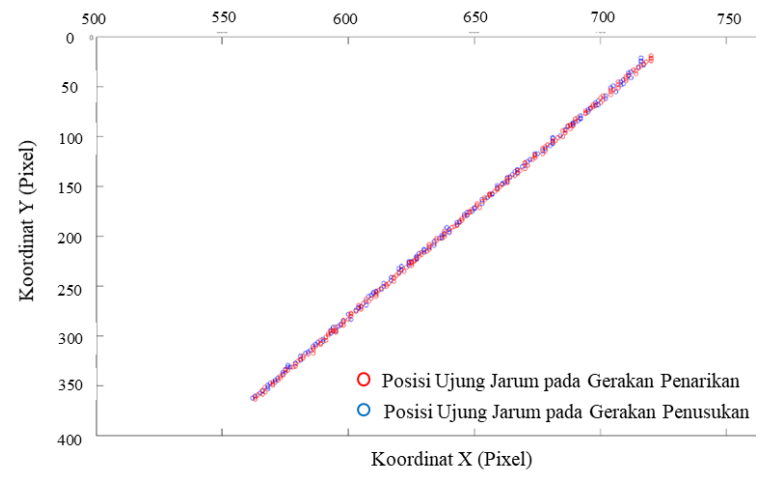

Gambar 10. contoh hasil posisi ujung jarum pada gerakan penusukan dan penarikan pada MATLAB

\section{Kesimpulan}

Pendekatan video motion analysis berdasarkan warna kontras optimal dapat digunakan sebagai pendekatan untuk mencari informasi-informasi mengenai posisi jarum yang akan digunakan sebagai data masukan parameter evaluasi kinerja sistem robot pemosisi jarum. Namun pendekatan ini masih memiliki kekurangan yang disebabkan oleh faktor internal dari kamera dan faktor eksternal, yaitu cahaya dari lingkungan sekitar.

\section{Daftar Pustaka}

[1] R. Brull, D. Wijayatilake, A. Perlas, V. Chan, S. Abbas and G. e. a. Liguori, "Practice Patterns Related to Block Selection, Nerve Localization and Risk Disclosure: A Survey of The American Society of Regional Anesthesia and Pain Medicine," Reg. Anesth. Pain Med., pp. 395403, 2008.

[2] H. Susanti, Suprijanto and D. Kurniadi, "TwoDimensional Mapping of Needle Visibility with Linear and Curved Array for Ultrasound-Guided Interventional Procedure," AIP Conference Proceedings, 2018. 